\title{
Redes sociales y Áreas Naturales Protegidas en la Zona Metropolitana de Monterrey, Nuevo León
}

\section{Social networks and Protected Natural Areas in the Metropolitan Zone of Monterrey, Nuevo Leon}

Gabriela de la Mora-de la Mora*

\begin{abstract}
Resumen
A partir del análisis de las dinámicas de interacción entre actores sociales clave, vinculados a la gestión de las áreas naturales protegidas y a la protección de los servicios ambientales hidrológicos en la Zona Metropolitana de Monterrey (ZMM), Nuevo León, se analizan las acciones que se llevan a cabo para lograr los objetivos de conservación. Se utiliza el análisis de redes para comprender la estructura y densidad de las relaciones sociales establecidas y su influencia en la definición de la gobernanza ambiental actual en la región, lo que permite destacar la existencia de alianzas estratégicas en materia de conservación y al mismo tiempo la falta de comunicación en otros sectores.
\end{abstract}

Palabras clave: Áreas Naturales Protegidas, servicios ambientales hidrológicos, conservación, redes y relaciones sociales, gobernanza ambiental.

\begin{abstract}
From the analysis of the dynamics of interaction between key social actors involved in the management of natural protected areas and the protection of watershed services in the metropolitan zone of Monterrey, Nuevo Leon, this article analyzes the actions performed to achieve conservation goals. Network analysis is used to understand the structure and density of social relationships and their influence on the definition of the current environmental governance in the region, highlighting the existence of strategic alliances in conservation and at the same time miscommunication in other sectors.
\end{abstract}

Keywords: protected natural areas, hydrological environmental services, conservation, Nntworks and social relations, environmental governance.

\footnotetext{
* Universidad Nacional Autónoma de México, Correo-e: gdlm@correo.crim.unam.mx
} 


\section{Introducción}

El número de proyectos de compensación por servicios ambientales implementados a nivel mundial ha crecido de manera importante en los últimos diez ańos, lo que ha abierto la posibilidad de explorar distintos enfoques de análisis más allá de las metodologías de valorización económica. Estos proyectos son resultado de procesos de concertación y colaboración entre diversos actores regionales clave, quienes tienen interés en la conservación de los recursos naturales y los servicios ambientales, especialmente los hidrológicos, así como en el mantenimiento del bienestar social en un contexto espacial específico.

Los objetivos de este trabajo son caracterizar y analizar las interacciones de actores sociales clave vinculados a los procesos de conservación de los ecosistemas naturales localizados cerca o dentro de la Zona Metropolitana de Monterrey (ZMM), así como los efectos que estas interacciones tienen en las dinámicas de gobernanza ambiental a nivel local. La relevancia de abordar este tema radica en que, cada vez más, se requiere una planeación estratégica vinculada al desarrollo urbano que evite, o al menos reduzca, la fragmentación y degradación del hábitat natural, la homogeneización en la composición de especies animales y vegetales, la interrupción de los sistemas hidrológicos y la modificación del flujo de energía y el ciclo de nutrientes de los ecosistemas naturales (Alberti y Marzluf, 2004).

Entre las múltiples causas asociadas a la fragmentación y degradación de los ecosistemas están, por ejemplo, los cambios de uso de suelo como consecuencia del crecimiento de ciudades que privilegian la expansión en el territorio más que la densificación en los espacios urbanos. Particularmente, Glaeser (2011) considera que la densificación puede contribuir a la conservación del ambiente porque supone que las distancias de traslado se reducen, lo que implica un menor consumo energético. En contraste, la dispersión urbana, centrada mayormente en el uso del automóvil y la baja densidad poblacional, representa altos costos ambientales como consecuencia del alto consumo energético producido por los desplazamientos y por la constante expansión de los límites de la ciudad hacia las periferias (Glaeser, 2011).

Asimismo, decisiones urbanísticas que favorecen el crecimiento urbano, en sitios donde las condiciones climáticas y ambientales son adversas, requieren de un mayor consumo energético y de recursos naturales (Glaeser, 2011) para lograr los estándares de confort y evitar riesgos a la salud humana, tal y como ocurre en ciudades localizadas en zonas desérticas (Harlan et al., 2006) donde la carencia de árboles y espacios verdes genera islas de calor (Stabler et al., 2005). 
Lo anterior cobra especial relevancia si se considera que para 2008 más de la mitad de las personas en el mundo vivían en zonas urbanas; se estima que esta proporción aumentará a dos tercios en 2050 (onU-Habitat, 2012). Europa, América Latina y América del Norte son regiones ya urbanizadas, mientras que África y Asia actualmente presentan las mayores tasas de urbanización (UNEP, 2013). Ante esta tendencia, la conservación y mantenimiento de zonas de amortiguamiento localizadas en la periferia de las ciudades es cada vez más relevante para lograr la provisión de diversos servicios ambientales, entre ellos, los hidrológicos.

Estos procesos complejos requieren la intervención de distintos órdenes de gobierno y diversos sectores de la sociedad en la toma de decisiones respecto a la planeación y uso del territorio, a fin de lograr su conservación y mantenimiento. Se trata de procesos dinámicos y subjetivos que, implícita y explicitamente, involucran relaciones de poder y conocimiento que pueden contribuir a la construcción de ciudades más sustentables a través del adecuado manejo de áreas naturales de mayor extensión (Lawrence, et al., 2013).

Esta investigación surge de un estudio exploratorio, en el que se analizan las interacciones entre diversos actores sociales en el marco de la implementación de estrategias para la conservación de áreas naturales protegidas y servicios ambientales hidrológicos en la periferia de la ZMM, en el noreste de México.

El trabajo está dividido en cuatro secciones: en la primera se esbozan algunos elementos teóricos básicos sobre las redes sociales, éstos servirán de base para explicar y caracterizar las interacciones entre los actores clave que participan en la gestión de las áreas naturales protegidas y la conservación de los servicios ambientales hidrológicos en la ZMM; en la segunda se explica la metodología utilizada; en la tercera sección se describen brevemente las áreas naturales protegidas consideradas y en la cuarta se analizan los principales resultados obtenidos a partir de la investigación de campo que permitió conocer las interacciones entre los actores clave, vinculados a la conservación en el área de estudio.

\section{Análisis de redes y gobernanza ambiental: esbozo teórico}

El análisis de las redes sociales inicia en la década de los años treinta con el desarrollo teórico de Jacob Levi Moreno, quien contribuyó a la comprensión del individuo como parte de una cadena de interacciones que lo vinculan con otros individuos, con su entorno y con diversas estructuras sociales. Para él, estos elementos eran constituyentes básicos de una dinámica inseparable de las acciones que llevan a cabo las personas para relacionarse entre sí (Fasano, 2010). John Barnes fue quien utilizó por 
vez primera el término red social para describir las complejas relaciones sociales establecidas entre pescadores de un poblado noruego (Mena, 2012; Fasano, 2010).

Las redes sociales también se han analizado desde la antropología con el propósito de comprender el funcionamiento de un conjunto de estructuras y dinámicas interpersonales en función de al menos una variable discriminante. Con lo anterior, se busca encontrar los patrones de amistad, relaciones personales e interconexiones en un grupo o entre grupos, para detectar las debilidades y fortalezas en esas interacciones (Friedrich, 1991).

Igualmente, la psicología ha utilizado el análisis de redes para explicar y comprender las acciones que llevan a cabo los individuos en los procesos de construcción de relaciones familiares, así como con otras personas o con su entorno (Fasano, 2010). Los teóricos de las relaciones sociales refieren la existencia de distintos niveles de análisis, es decir, los niveles macro, meso y micro; algunos de los más utilizados por la sociología son los individuales, grupales, organizacionales, comunitarios, institucionales, sociales y los de orden global.

Los estudios de redes no utilizan muestras, al menos en el sentido convencional, sino que intentan incluir a todos los actores de una población o poblaciones determinadas (Hanneman, 2000). Una red social consiste en la existencia de relaciones que pueden ser entendidas como acciones, actividades, transacciones, obligaciones, sentimientos $\mathrm{u}$ otro tipo de conexiones entre pares o subgrupos de actores; es decir, personas, organizaciones individuales o colectividades (Faust, 2002). La perspectiva de redes predispone al investigador a focalizar su atención en múltiples niveles de análisis de manera simultánea, pues agrupa a distintos actores de manera anidada (Hanneman, 2000).

Gráficamente las redes se componen de nodos y líneas, los que en conjunto constituyen la estructura de la red social (Mena, 2012; Hanneman, 2000). Los nodos son los actores sociales que interactúan en un espacio y tiempo. En el presente caso de estudio se consideran diversos actores sociales clave involucrados en el tema de la conservación de las ANP gestionadas por el gobierno federal y estatal, localizadas en la ZMM o en su periferia. En los siguientes apartados se definirán los actores considerados, así como las características fundamentales de las ANP incluidas en el estudio.

Las líneas se refieren a las interacciones y vínculos que establecen entre sí los actores sociales, más que a los atributos que les caracterizan. Se pueden distinguir diversos tipos de relaciones según el número y la manera en que se forman esos lazos: su fortaleza, cercanía, grado de formalidad y duración, si se trata de lazos directos o indirectos, etcétera. Las redes existen en distintos niveles, es decir, pueden ser personales, 
corporativas, nacionales, entre otras; esos tipos de relaciones no son excluyentes entre sí.

Las redes son importantes porque implican obligaciones y expectativas, así como un sentido de confianza, reciprocidad, flexibilidad, un toma $y$ daca (Carruthers y Babb, 2000). La estructura de las conexiones permite comprender cómo se organizan e interactúan los actores, el lugar que ocupan en la red, su centralidad y poder, su jerarquía en la toma de decisiones (Berkes, 2002). La mayor o menor centralidad, es decir, la lejanía o cercanía respecto del centro, puede demostrar el grado de disparidad existente en la red, la desigual distribución del poder entre los actores, además de los vacíos estructurales que pueden denotar la ventaja o desventaja relativa que unos tienen sobre otros en un contexto socio-político específico (Fang, 2011).

La mayoría de las personas, grupos y organizaciones tienden a generar un número limitado de lazos fuertes, probablemente porque los actores sociales tienen recursos limitados en términos de energía, tiempo y capacidades cognitivas. Sin embargo, las estructuras sociales pueden desarrollar un grado considerable de orden y solidaridad con relativamente pocas conexiones (Hanneman, 2000), por lo tanto, la forma en que interactúan los actores sociales puede expresar solidaridad y formas complejas de organización; o por el contrario, la ausencia de vínculos refleja aislamiento y falta de comunicación. La relevancia o no de la incomunicación entre actores sociales estará en función de qué tan necesario es que se establezcan esas relaciones y las consecuencias que puede llegar a tener este hecho.

Al analizar la adyacencia es posible conocer la conexión que unos actores mantienen con otros y la manera en que se integra la red en su conjunto (Mena, 2012), así como su contribución en la generación de aprendizaje, mecanismos de ayuda, influencia o comunicación entre los actores involucrados (Hanneman, 2000). La densidad en las redes sociales puede proveer información respecto a la rapidez en la difusión de la información entre los actores; a medida que aumenta la densidad de las instituciones sociales que están operando, la posibilidad de interacción entre dos o más instituciones se incrementa (Young, 2002).

Las relaciones entre actores de distintas escalas (por ejemplo instancias gubernamentales de nivel municipal, estatal y federal) pueden ser simétricas-asimétricas, multidireccionales-unidireccionales o generar vínculos estratégicos con el fin de mejorar la eficiencia en la operación de uno o más arreglos institucionales (Young, 2002). Estas interacciones sirven para diseñar políticas y establecer conexiones intencionales en la persecución de metas individuales o colectivas (Young, 2002). La distancia entre los actores que conforman una red implica que, cuando ésta es grande, puede 
tomar un largo tiempo la difusión de información en una población o grupo; mientras que los actores que guardan mayor proximidad entre sí pueden ejercer mayor poder que aquéllos que están más distantes (Hanneman, 2000).

Las relaciones y redes sociales son relevantes en el contexto de la gobernanza porque evidencian el mayor o menor flujo de información y conocimientos anclados en las convicciones y compromisos de los actores involucrados (Mena, 2012), así como la existencia de capital social entre ellos, el cual se desarrolla a través del establecimiento de acciones colaborativas (Kazushige, 2014). La gobernanza se refiere a los medios y acciones que permiten dirigir y coordinar gestiones para la consecución de objetivos -individuales u organizacionales- con la intención de crear bienes y valores públicos.

Las acciones colaborativas pueden ser concebidas como parte de un sistema de redes, pues se establecen entre actores interdependientes que involucran a diversas organizaciones o actores quienes, en conjunto, son capaces de mantener una cierta estabilidad estructural (Imperial, 2005). La presencia o ausencia de relaciones entre actores sociales en un contexto de gobernanza ambiental implica la posibilidad de analizar, difundir y utilizar sistemáticamente información útil para la adecuada toma de decisiones (Mena, 2012), así como la posibilidad de generar alianzas y estrategias entre actores públicos y privados (híbridos) a fin de favorecer el bien común, es decir, la protección de ciertos usos del suelo que contribuyan a su manejo sustentable (Lambin et al., 2014).

Analizar las redes sociales presentes en un contexto sociopolítico específico ayuda a comprender las estructuras de autoridad existentes; es decir, si se trata de arreglos institucionales centralizados (unicéntricos) o descentralizados (policéntricos); particularmente, estos últimos tienden a generar economías de escala y distribuir normas y reglas interdependientes entre autoridades de diversas jurisdicciones (Ostrom et al., 1993).

\section{Metodología}

La información se obtuvo del análisis de fuentes biblio-hemerográficas y de la realización de entrevistas semi-estructuradas a actores clave. Las entrevistas se llevaron a cabo a lo largo de 2012 a los representantes o directores de las ANP en el estado de Nuevo León, tanto federales como estatales y privadas que se localizan en la ZMM o en su periferia; los encargados de la toma de decisiones en materia ambiental de instancias federales y estatales vinculadas a temas hídricos, forestales y de conservación de ANP; los encargados de la toma de decisiones en materia ambiental o ecológica en los municipios pertenecientes a las demarcaciones 
donde se localizan las áreas naturales protegidas comprendidas en la ZMM; ${ }^{1}$ los representantes de la sociedad civil organizada interesados en la conservación de ANP, y que están vinculados al tema de los servicios ambientales hidrológicos. Los actores clave entrevistados fueron seleccionados por su relevancia en el sector de la conservación y su participación en la gestión de las áreas naturales protegidas analizadas. Es importante precisar que por razones ajenas a esta investigación no todos los actores estuvieron disponibles para proporcionar información. ${ }^{2}$

Para recolectar información se utilizaron varios cuestionarios de entrevistas con preguntas semi-estructuradas relacionadas con (1) el involucramiento de los actores sociales entrevistados en la generación de los marcos legales (p.e. decretos) e institucionales (p.e. planes de manejo) que regulan las acciones de conservación y la gestión de las áreas naturales protegidas, así como su opinión sobre su cumplimiento y efectividad para lograr los objetivos de conservación; (2) la existencia de mecanismos de comunicación y colaboración (formales e informales) entre distintos actores vinculados a la gestión de las áreas naturales protegidas en la región y los principales temas atendidos relacionados con la conservación y las áreas naturales protegidas; (3) los principales problemas que enfrentan los actores involucrados en la gestión de las áreas protegidas para lograr los objetivos de conservación; (4) las acciones que se llevan a cabo para cuantificar y monitorear la producción de servicios ambientales en las ANP, con énfasis en los servicios hidrológicos y la opinión sobre los esquemas de compensación por servicios ambientales como herramienta de conservación.

La información se sistematizó empleando técnicas cualitativas. Por medio de la codificación deductiva e inductiva se encontraron patrones de interacción que fueron graficados empleando el programa Ucinet. Dichos diagramas permitieron identificar la estructura de las interacciones de los actores clave, (gráficamente se pueden distinguir por sus formas y dimensiones, por ejemplo, las instancias del gobierno federal son círculos; las del gobierno estatal cuadros; las del gobierno municipal triángulos; las universidades rombos y las organizaciones no gubernamentales cuadros cuadriculados).

En el siguiente apartado se caracterizan las ANP localizadas en la ZMM consideradas en este estudio.

\footnotetext{
${ }^{1}$ Se refiere a Apodaca, Escobedo, Guadalupe, Monterrey, Santa Catarina, San Nicolás, San Pedro Garza García y Santiago.

${ }^{2}$ A nivel estatal no fue posible colectar información de los sectores ambiental e hídrico; así como en tres municipios (Cadereyta, García y Juárez) y algunas organizaciones no gubernamentales; las causas de ello están relacionadas con asuntos que escapan al control del investigador.
} 


\section{Caracterización de las Áreas Naturales Protegidas consideradas en el estudio}

La superficie total de ANP bajo algún tipo de régimen de protección en el estado de Nuevo León es de aproximadamente 519,000 hectáreas, de las cuales poco más de 311,000 se localizan en los municipios comprendidos en la $\mathrm{ZMM}^{3}$ en los que se asienta aproximadamente $88 \%$ de la población del estado (INEGI, 2010). El área de análisis comprende trece ANP, dos de las cuales están bajo resguardo del gobierno federal y abarcan $59 \%$ de la superificie del estudio; 10 están bajo resguardo del gobierno del estado de Nuevo León y comprenden $40.5 \%$ de la superficie, y un área está bajo resguardo de actores privados y representa $0.5 \%$ de la superficie analizada. ${ }^{4}$ En el mapa I se puede ubicar la zona de estudio y en el cuadro 1 se describen brevemente las características generales de estas áreas naturales protegidas.

En la región de análisis existe una heterogeneidad y complejidad importante en la gestión de las ANP, lo que se evidencia a través de los diversos marcos institucionales que regulan dichas áreas (como son las declaratorias de áreas protegidas federales y estatales y los respectivos programas de manejo). Particularmente, la gestión de las áreas protegidas por la federación está a cargo de los representantes de las respectivas direcciones dependientes de la Comisión Nacional de Áreas Naturales Protegidas (Conanp). Estas autoridades han experimentado procesos largos de concertación y aprobación de los programas de manejo con los actores locales involucrados en cada una de las áreas protegidas.

Lo anterior pone en evidencia las dificultades existentes para llegar a acuerdos sobre los usos del territorio y los recursos naturales entre los usuarios y propietarios de estas áreas; concretamente, este proceso en el PNCM ha retrasado la aprobación del actual borrador de programa de manejo. En el caso del MNCs, el proceso de concertación del programa de manejo fue largo, pues llevó varios ańos de negociación hasta que finalmente se publicó a principios de 2014.

\footnotetext{
${ }^{3}$ Según la delimitación hecha por Sedesol, Conapo e INEGI (2012) los municipios comprendidos en la ZMM en los que coinciden las superficies de las ANP y que fueron consideradas en esta investigación son Apodaca, García, San Pedro Garza García, Escobedo, Guadalupe, Juárez, Monterrey, San Nicolás de los Garza, Santa Catarina, Santiago y Cadereyta. Es importante seńalar que parte de las superficies de las ANP se localizan en municipios fuera de la ZMM, es el caso de Allende, Montemorelos, Rayones, Mina, Hidalgo y Abasolo, los cuales no fueron considerados en el estudio, al igual que Carmen y Salinas Victoria.

${ }^{4}$ Se ha incluido el Parque Ecológico Chipinque en el cuadro porque se encuentra en territorio del Parque Nacional Cumbre de Monterrey (PNCM), sin embargo, éste se constituyó como una Asociación de Beneficencia Privada (ABP) que es administrado de manera independiente por un patronato que integra representantes de la iniciativa privada (Cemex, Femsa, Alfa, Cydsa, Grupo Imsa, Pulsar y Vitro), el gobierno federal, el estatal y el municipio de San Pedro. Este parque cuenta con un programa de manejo que se actualiza periódicamente a fin de promover la conservación, restauración y protección de los recursos naturales comprendidos en el mismo.
} 


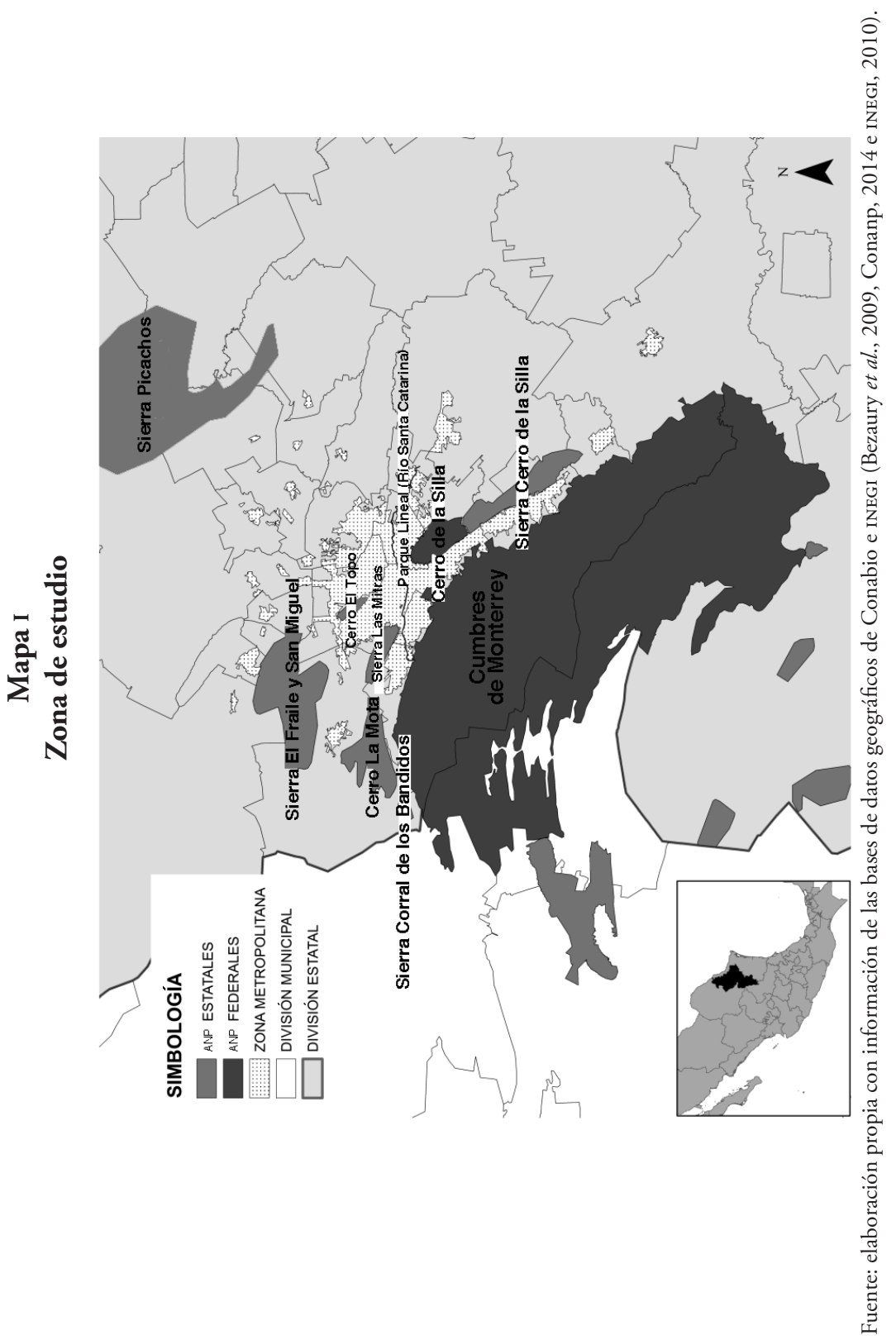




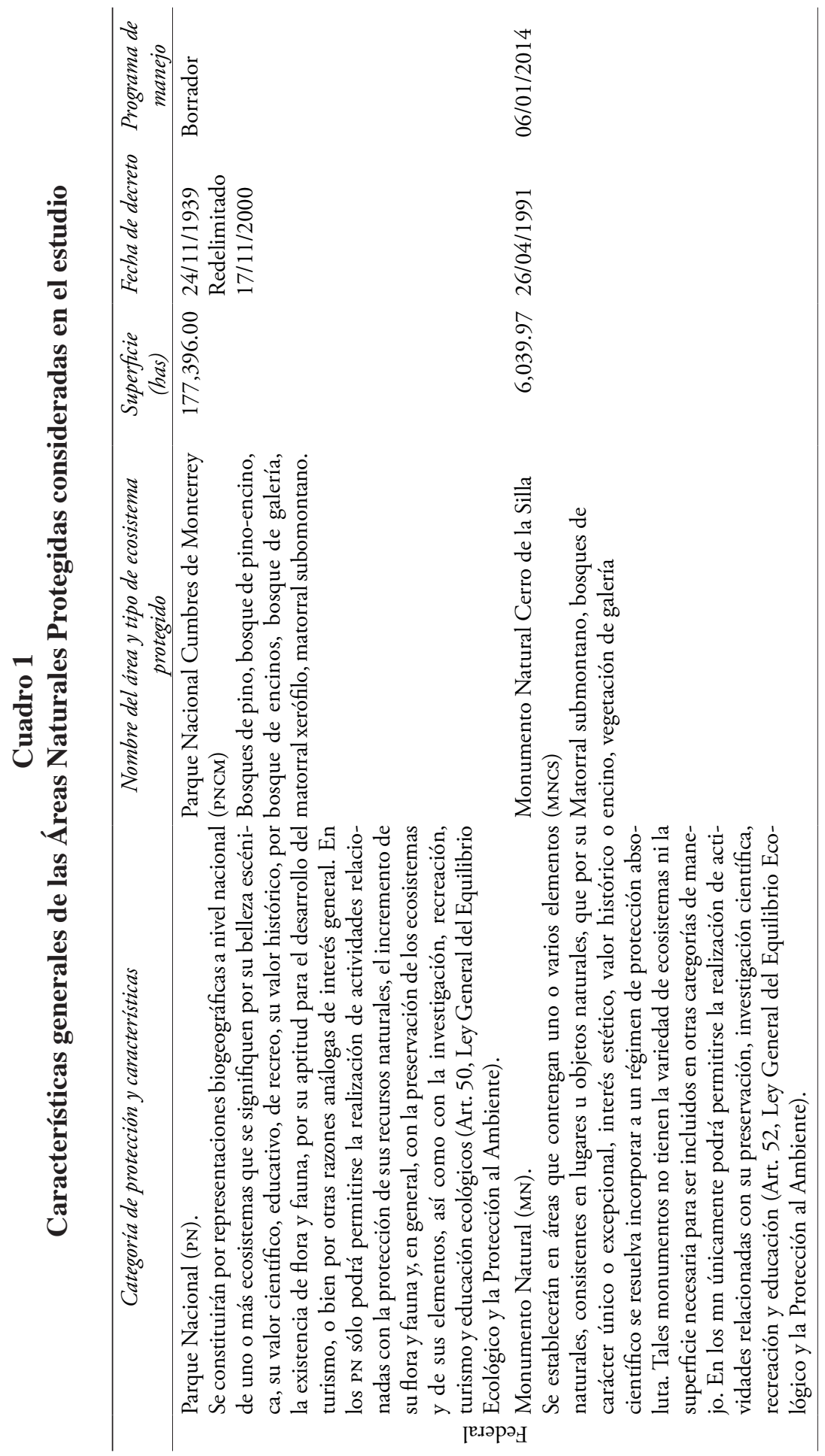




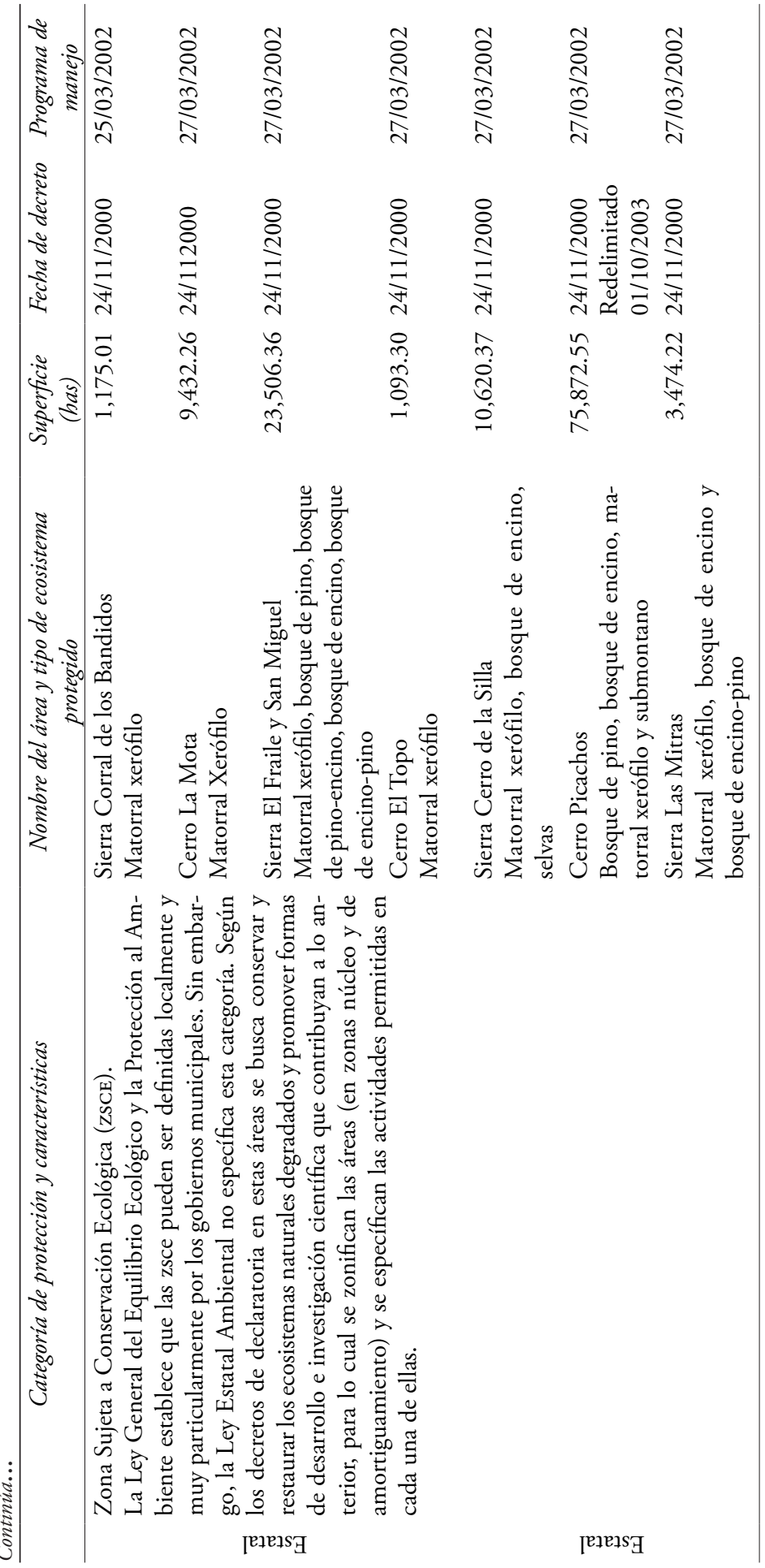




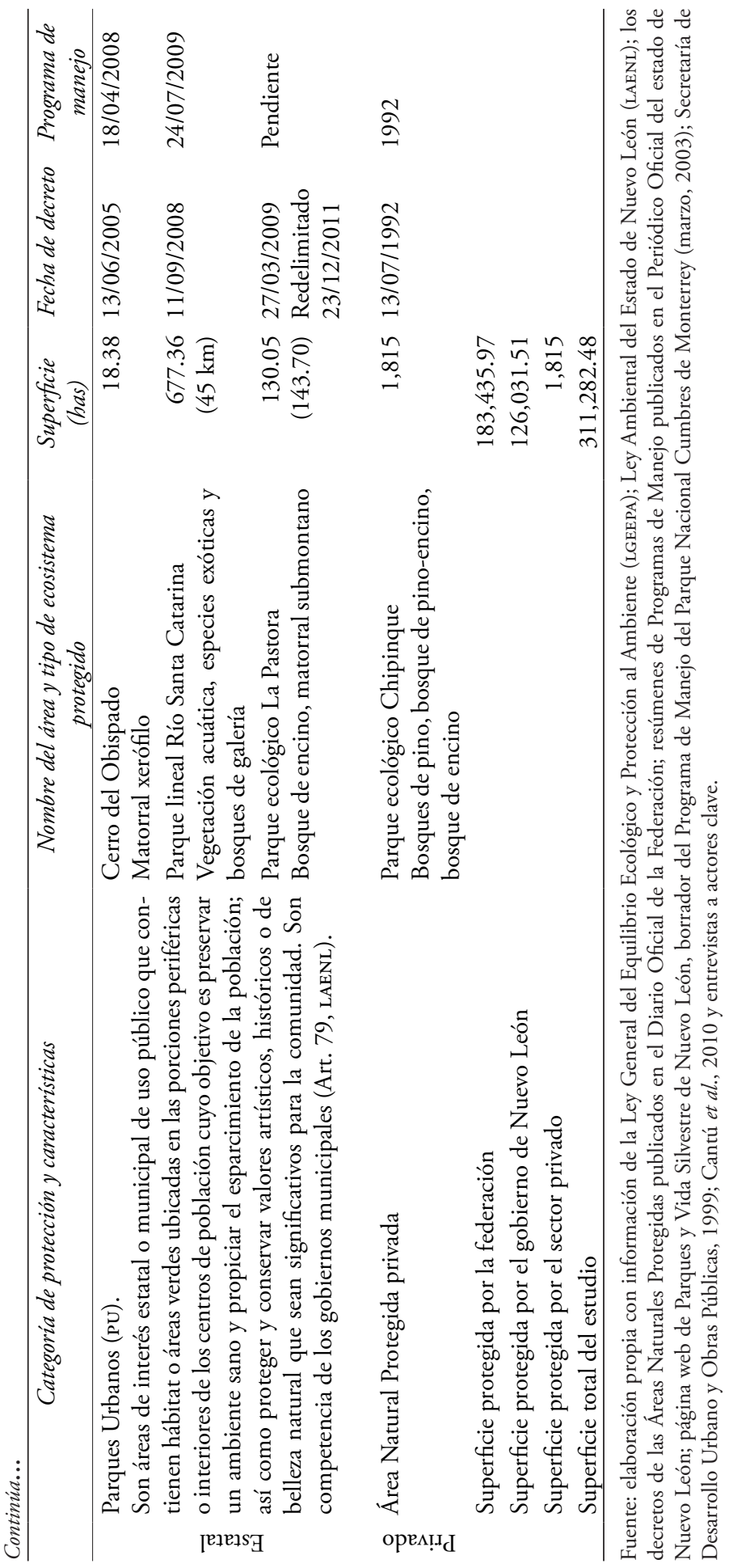


Por su parte, las áreas protegidas por el gobierno del estado están a cargo de Parques y Vida Silvestre (PyVS), que es un organismo descentralizado de la administración pública estatal, con personalidad jurídica, patrimonio propio y autonomía técnica y de gestión. En este caso, la mayoría de las declaratorias de protección se generaron en un mismo periodo a partir de una iniciativa sustentada en un estudio científico técnico elaborado por especialistas de la Universidad Autónoma de Nuevo León y del Instituto Tecnológico y de Estudios Superiores de Monterrey (ITESM). Dicha iniciativa fue apoyada por el gobierno de Nuevo León con la finalidad de proteger diversos ecosistemas de montańa localizados en la ZMM, entre otros sitios relevantes de la entidad.

A diferencia de los procesos ocurridos con las áreas protegidas por la federación, la aprobación de la mayoría de los programas de manejo no tuvo oposición, ya que dos años después de las declaratorias se generaron de manera simultánea los programas de manejo respectivos, los cuales desde entonces no han sido actualizados. Sin embargo, este fenómeno no se repitió en el parque ecológico La Pastora y el parque lineal del Río Santa Catarina. En el primer caso se detuvo la aprobación del programa de manejo porque se presentó una polémica por la cesión de 25 hectáreas de terreno en comodato a la empresa Fomento Económico Mexicano (Femsa) para la construcción del nuevo estadio de futbol Monterrey, éste se encuentra en la zona de amortiguamiento del parque urbano ubicado en el municipio de Guadalupe, cerca del río La Silla.

El segundo caso fue polémico porque, aún cuando esta área protegida cuenta con un programa de manejo, el gobierno de Nuevo León y los municipios que tienen la custodia del cauce (Monterrey, Santa Catarina, Guadalupe y San Pedro), así como dueños de concesiones, comerciantes y desarrolladores inmobiliarios desean promover proyectos urbanos y áreas recreativas en el cauce del Río Santa Catarina (que en 2010 fue devastado por el paso del huracán Álex) contraponiéndose a lo dispuesto por la Conagua (Cepeda, 2013; Zuñiga, 2013).

En el siguiente apartado se describen las relaciones e interacciones más relevantes entre los actores sociales vinculados a los temas de conservación en las áreas naturales protegidas en la ZMM. Asimismo, se analizan algunos de los resultados que tienen esas interacciones en relación con la gobernanza ambiental local.

\section{Relaciones sociales y conservación en la ZMM}

La participación e interacción de actores sociales clave en el marco de la gestión de las ANP ha sido un elemento importante en el diseño e implementación de acciones que contribuyen al mantenimiento y conservación 
de los servicios ambientales hidrológicos. A partir del número de interacciones registradas entre los actores analizados se identificó en su jerarquía el siguiente orden: sector académico, Consejo Estatal Forestal (CEF), Comisión Nacional Forestal (Conafor), Parque Nacional Cumbres de Monterrey (PNCM), Procuraduría Federal de Protección al Ambiente (Profepa), Comision Nacional del Agua (Conagua), Monumento Natural Cerro de la Silla (MNCS), Municipio de Santa Catarina, Comisión Nacional de Áreas Naturales Protegidas (Conanp), Municipio de San Pedro, Secretaría de Medio Ambiente y Recursos Naturales de Nuevo León, Servicios de Agua y Drenaje de Monterrey (SADM), municipio de Apodaca, Fondo de Agua Metropolitano (faM), municipio de Monterrey, Pronatura, Parque ecológico Chipinque, Parques y Vida Silvestre (PrVS), municipio de Guadalupe, Escobedo, Santiago, Fundación Femsa, municipio de San Nicolás, Secretaría de Medio Ambiente y Recursos Naturales (Semarnat), Reforestación extrema, The Nature Conservancy (TNC) y Guardianes de la Huasteca.

Por razones de espacio, a continuación se analizan las características y formas de interacción más relevantes de los siguientes actores: en primer lugar las instituciones académicas; en segundo sitio el CEF; en tercer lugar la Conafor; en cuarto lugar las direcciones de las ANP federales y estatales y en quinto lugar las interacciones entre los gobiernos municipales. Asimismo, como resultado de estos procesos, se analiza la emergencia de un nuevo actor que ha catalizado parte de los esfuerzos de conservación vinculados tanto con las ANP como con los servicios ambientales hidrológicos en la ciudad de Monterrey, es decir, el Fam. Finalmente, mencionamos brevemente algunas formas representativas de participación de la sociedad en estos procesos, a partir de la ejecución de acciones de socialización y difusión de información que otros actores sociales han llevado a cabo, ya que la participación ciudadana es un componente vital en la construcción de la gobernanza ambiental a nivel local.

Las instituciones académicas que más destacan en la participación de las redes de conservación a nivel local son la UANL y el ITESM, ambas han llevado a cabo aportaciones científicas y técnicas, además de ayudar en la formulación y diseño de políticas de intervención y acciones vinculadas a la gestión de las ANP y la conservación de los servicios ambientales especialmente los hidrológicos. Los actores con los que se relacionan estas instancias incluyen organismos del gobierno federal y estatal (por ejemplo Conafor, Conagua, Conanp, MNCS, PPNCM, PyVS), gobiernos municipales, organizaciones no gubernamentales (por ejemplo Pronatura y TNC), e iniciativa privada (Fundación Femsa), el Fam, entre otros.

Por su parte, el Consejo Estatal Forestal funge como un órgano de asesoría, supervisión, vigilancia, evaluación, concertación y seguimiento 
en la aplicación de criterios e instrumentos de política forestal y emisión de recomendaciones; asimismo participa en la elaboración de planes, programas y normas (Art. 67, Ley de Desarrollo Forestal Sustentable del Estado de Nuevo León, LDFSNL). Su intervención ha sido fundamental en los procesos de autorización o rechazo de permisos de cambio de uso de suelo en terrenos forestales circundantes a la ciudad de Monterrey, entre los que se incluyen superficies comprendidas en Áreas Naturales Protegidas.

Sus funciones se fortalecen con la participación de actores relevantes a nivel regional y local en el tema de la conservación, entre ellos, los miembros de los consejos regionales y sus representaciones municipales, el ejecutivo del estado, el representante estatal de la Comisión Nacional Forestal, los productores sociales e industriales forestales, las organizaciones civiles, académicos o cualquier persona moral o física reconocida en ese ámbito. Los actores entrevistados reportan que la actuación de este Consejo ha sido fundamental para regular el crecimiento y expansión urbana, que es una de las principales amenazas que enfrentan las direcciones de las ANP, tal y como se explicará más adelante.

La Conafor ha jugado un papel relevante en el Consejo porque preside la secretaría técnica, lo que le ha permitido estrechar sus relaciones con otras instancias del gobierno federal y estatal como la Secretaría de Medio Ambiente, la Secretaría de Desarrollo Sustentable de Nuevo León, las autoridades de los gobiernos municipales, organizaciones de la sociedad civil (Pronatura, Reforestación Extrema, etc.) y con los encargados de la gestión de las áreas naturales protegidas locales, es decir, las autoridades del Parque Ecológico Chipinque, del PNCM, del MNCS y de PyVS, además mantienen una estrecha relación con la UANL y el ITESM. Igualmente participa activamente en la conformación del faM de la ciudad de Monterrey.

En cuanto a las relaciones de colaboración que establecen los directores de las ANP con otros actores sociales y políticos, encontramos que las áreas protegidas por el gobierno federal tienen mayor centralidad y redes de relaciones más diversificadas respecto a la gestión de las áreas naturales protegidas por el gobierno de Nuevo León. Particularmente, el PNCM es el que ocupa la mayor centralidad y una red más amplia de relaciones. En la figura I se muestra la estructura de la red de relaciones que mantiene la dirección del PNCM y los distintos actores con los que colabora.

Las autoridades del PNCM mantienen relaciones con los gobiernos municipales metropolitanos en donde se localiza el parque; es decir, Monterrey, Santa Catarina, San Pedro y Santiago, entre otros. En el caso del municipio de Santa Catarina la relación es más estrecha gracias a que se implementó el Programa de Guarda Ecológico desde 2010; este programa surge con el objetivo de fomentar la cultura ambiental dentro del municipio y entre las autoridades municipales, así como proteger los 


\section{Figura I \\ Parque Nacional Cumbre de Monterrey (PNCM)}

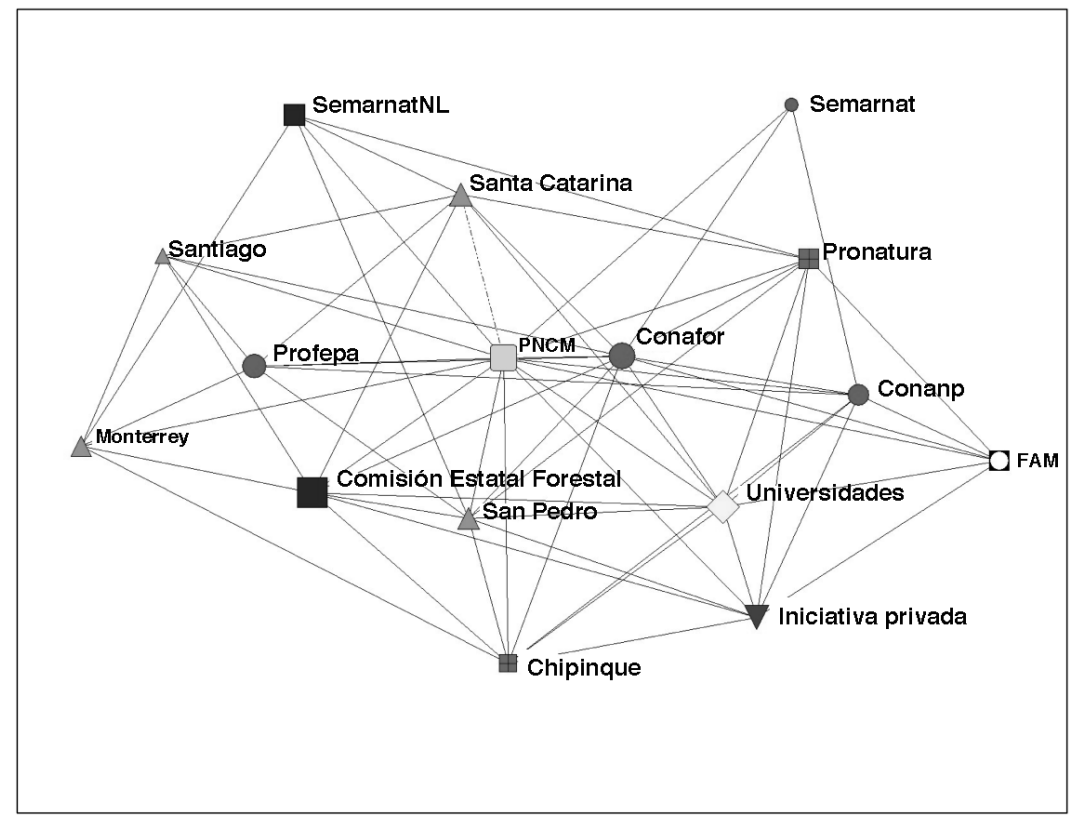

Fuente: elaboración propia.

recursos naturales y la integridad de la porción PNCM que se localiza en ese municipio. La figura de guarda ecológico carece de sustento legal a nivel municipal, sin embargo esto no ha impedido que las autoridades del PNCM firmen convenios con el guarda, a fin de coadyuvar en las actividades de vigilancia en el parque y sus inmediaciones.

Las autoridades del parque, además, mantienen una estrecha relación con organismos gubernamentales del orden federal (Semarnat, Conafor y Profepa) y a nivel estatal participan activamente en el Cef, así como con organizaciones no gubernamentales como Pronatura y con el Parque Ecológico Chipinque, entre otros. Su participación en el fam es clave, ya que se busca la realización de actividades de reforestación y restauración dentro del parque.

Los principales problemas detectados en la gestión del PNCM son la presión que ejerce la expansión de la frontera agropecuaria, la tala inmoderada y los asentamientos humanos, lo que afecta los ecosistemas naturales como consecuencia del cambio de uso de suelo5 (Saldívar, 2007). Un ejemplo destacable sobre la presión que el crecimiento urbano ejerce sobre estas áreas es el proyecto de urbanización en la zona de La Huaste- 
$\mathrm{ca}^{6}$ conocido como Valle de Reyes, el cual tiene su origen en 2003, cuando miembros de un grupo industrial plantearon llevar a cabo desarrollos residenciales de alto nivel socioeconómico en una zona que comprendía 2,400 hectáreas del PNCM.

Grupos sociales se manifestaron en contra del proyecto, con lo que inició una disputa jurídica que según Azuela y Musseta (2009) se libró en dos sentidos: 1) en juicios de amparo en los que los propietarios cuestionaron la legalidad de las restricciones implícitas en los decretos que crean y re-delimitan el parque en 1939 y 2000; 2) en el proceso de planeación a nivel municipal, donde se clasifica el suelo como urbanizable y no urbanizable. Melé (2003) menciona que en 2003 un juez federal decretó la invalidez jurídica del parque en esa superficie dejando de ser parte del PNCM. Las consecuencias de este suceso fueron la suspensión del proyecto inmobiliario y la perdida de una parte de la superficie del parque, con lo que se dio un golpe a las políticas de conservación ambiental en México en el terreno jurídico, abriéndose la posibilidad de interponer amparos en parques nacionales donde los dueńos quieran cambiar los usos del suelo (Azuela y Musseta, 2009).

En el caso del MNCS, la dirección de esta ANP mantiene relaciones estrechas con diversas instancias del gobierno federal vinculadas con los temas ambientales (Semarnat, Conafor, Conanp, Profepa y Conagua), y del gobierno estatal (Secretaría de Desarrollo Sustentable de Nuevo León y CEF ), así como con los gobiernos municipales de Guadalupe, Monterrey y Juárez, donde se localiza el monumento; organizaciones de la sociedad civil (Reforestación Extrema), universidades e iniciativa privada. En la figura II se observa la estructura de relaciones que tiene esta ANP con distintos actores sociales y políticos locales.

Igual que sucede en el PNCM, uno de los principales problemas que desde hace décadas ha puesto en riesgo la integridad de esta emblemática área protegida es el crecimiento urbano. Desde mediados de los años ochenta y como consecuencia de la falta de programas sectoriales municipales para regular el crecimiento urbano, el estado expidió autorizaciones para la construcción de fraccionamientos y desarrollos habitacionales en la parte baja del monumento, lo que llevó a actores de la sociedad civil a llamar la atención de las autoridades municipales y estatales para detener el crecimiento (Conty, 2010).

Un proceso similar se vivió con el proyecto de construcción del Arco Vial Sureste ${ }^{7}$, con el cual se pretendía construir una vialidad de 19.8

\footnotetext{
${ }^{6}$ Según lo señalan Cantú y colaboradores (2010: 171) en la zona de La Huasteca se produce $10 \%$ de los $11 \mathrm{~m}^{3} / \mathrm{s}$ que demanda esa ciudad y su zona metropolitana, por lo que el proyecto de urbanización afectaría la provisión de agua en la ciudad.

${ }^{7}$ Para más detalles sobre el caso ver el trabajo de Aguilar-Barajas (2011).
} 


\section{Figura II \\ Monumento Natural Cerro de la Silla (MNCS)}

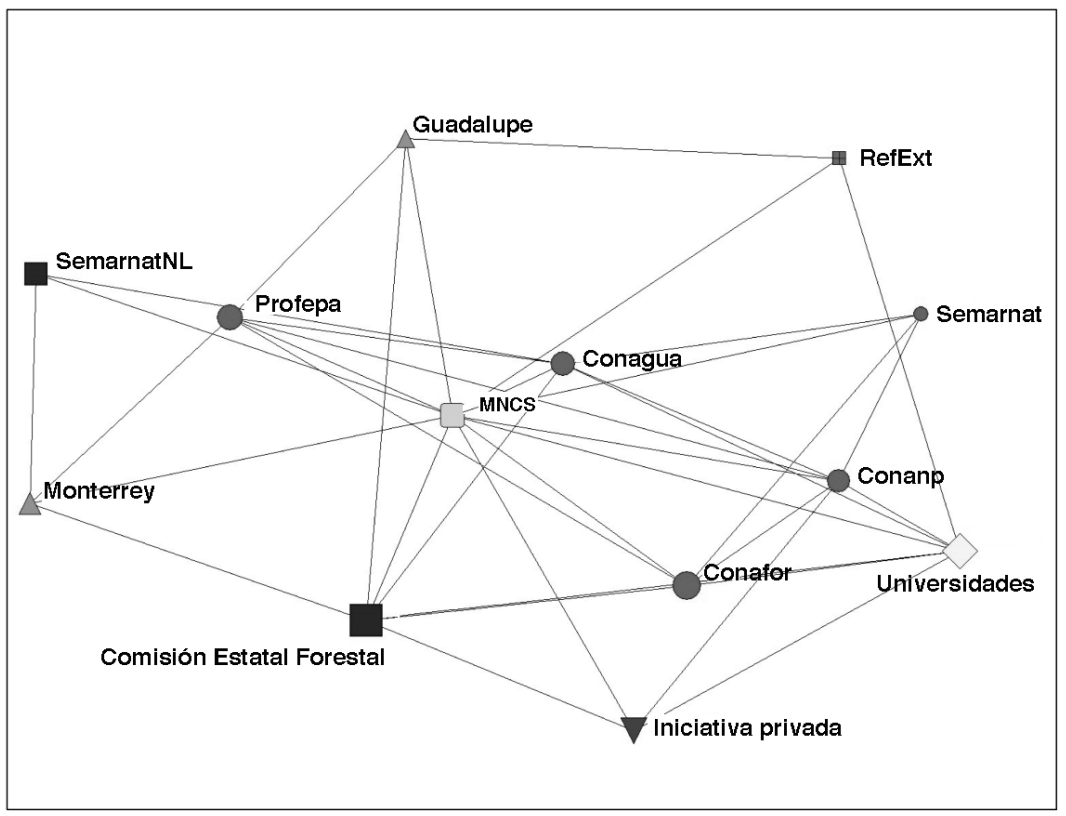

Fuente: elaboración propia.

kilómetros que comunicara la carretera a Reynosa, en el municipio de Juárez, con la carretera nacional a la altura de Los Cristales en Monterrey, a través de un túnel de 1.8 kilómetros de longitud que atravesaría el área protegida. La inversión se estimaba en cerca de 2 mil 500 millones de pesos, pero gracias a la movilización de la sociedad civil y a un proceso de toma de decisiones errático por parte de las autoridades se canceló, lo que evitó la transformación de la fisonomía del MNCs y de el área estatal protegida contigua denominada Sierra Cerro de la Silla (Cantú et al., 2010; Aguilar-Barajas, 2011).

Por su parte la red de relaciones de PVYS está menos diversificada que la de las áreas protegidas por la federación. Esta instancia mantiene relaciones cercanas con instituciones académicas y la Conafor; a nivel estatal participa activamente en el CEF. Sus relaciones con los gobiernos municipales son reducidas en número y aunque no es atribución específica de estos últimos cuidar de las áreas protegidas, su cooperación en la vigilancia de las ANP estatales contribuiría de manera importante a su mantenimiento.

Asimismo, las interacciones de PyVS con el sector federal de áreas protegidas es débil. Con las autoridades del Parque ecológico Chipinque existe un vinculo más sólido, su principal relación con las organizaciones 
de la sociedad civil organizada se orienta a Pronatura, particularmente la organización Guardianes de la Huasteca percibe que a PyVS le hace falta establecer mejores canales de comunicación con ellos y los usuarios de los parques localizados en la zona de La Huasteca. PyVS participa activamente en el FAM, ya que existe interés por generar estrategias de conservación en algunas de las ANP relevantes para la provisión de servicios ambientales hidrológicos para la ciudad de Monterrey. En la figura III se observa la estructura de las relaciones de PyVS.

\section{Figura III}

\section{Parques y Vida Silvestre}

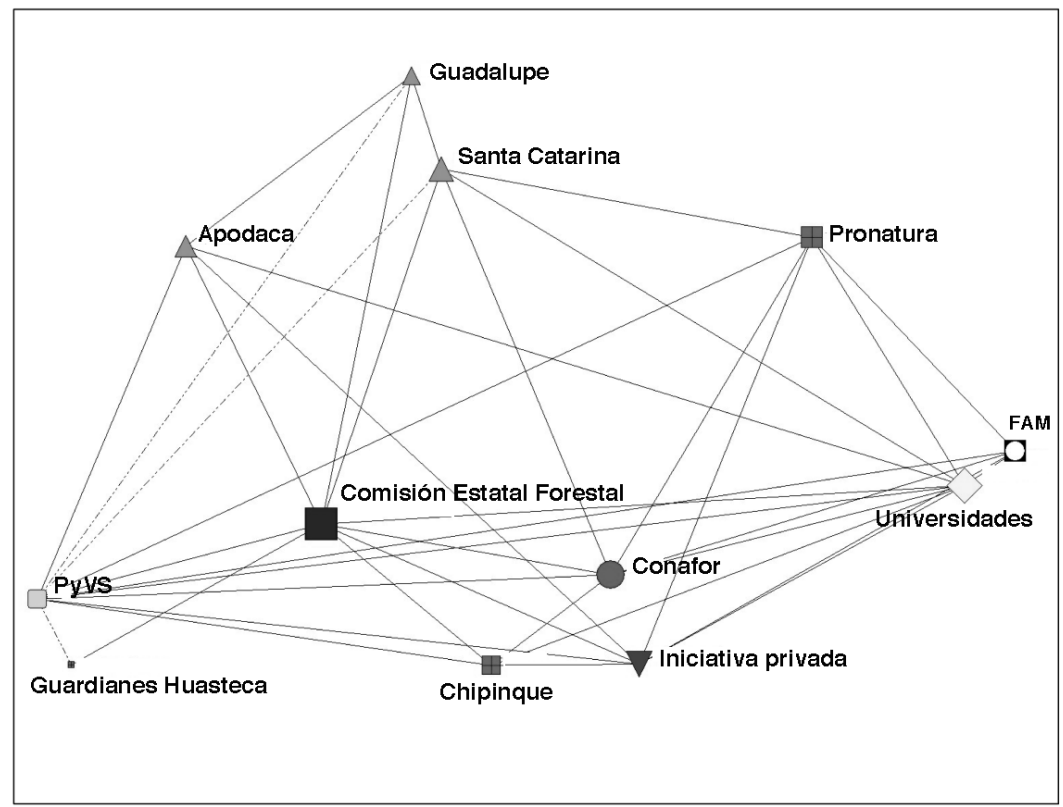

Fuente: elaboración propia.

Por otro lado, los gobiernos de los estados tienen la facultad de establecer, regular, administrar y vigilar las áreas naturales protegidas previstas en la legislación local y cuentan con la participación de los gobiernos municipales (LGEEPA, art. 7, fracc. V). Asimismo, los municipios pueden aplicar los instrumentos de política ambiental previstos en las leyes locales en la materia, así como la preservación y restauración del equilibrio ecológico y la protección al ambiente en bienes y zonas de jurisdicción municipal en las materias que no estén expresamente atribuidas a la federación o a los estados (LGEEPA, art. 8, fracc. II). 
Los municipios pueden crear y administrar zonas de preservación ecológica, parques urbanos, jardines públicos y demás áreas análogas previstas por la legislación local (LGEEPA, art. 8, fracc. V). Con base en lo anterior y pese a que para los gobiernos municipales es un mandato legal la conservación de las ANP en los municipios analizados, este tema no ocupa un lugar central en sus agendas. En las entrevistas a funcionarios municipales de ecología y ambiente se les pidió que enunciaran los principales temas a los que se da atención en sus respectivas administraciones, el asunto que más se mencionó fue la educación ambiental en escuelas y empresas (27\%); en segundo lugar la arborización y reforestación urbana (23\%) y las campañas de reciclaje (23\%); en tercer sitio la contaminación atmosférica, de suelo y agua (14\%) y en cuarto lugar la conservación de flora y fauna (13\%).

Pese a que el tema de la conservación ocupa el último lugar entre las preocupaciones de las autoridades municipales entrevistadas, éstas reconocen que los principales problemas relacionados con las ANP son la falta de vigilancia y la carencia de convenios de colaboración con otros órdenes de gobierno e instancias gubernamentales que contribuyan a limitar el crecimiento urbano y ayuden a respetar los límites de las áreas protegidas.

La interacción entre los encargados municipales de los temas ambientales está influida por la vecindad geográfica. El municipio de Monterrey es el que ocupa la mayor centralidad al relacionarse con sus homólogos de los municipios de Santiago, San Nicolás y Escobedo, mientras que Apodaca, Santiago y San Nicolás ocupan la segunda jerarquía al relacionarse cada uno de ellos con dos municipios; Guadalupe, Santa Catarina y Escobedo ocupan el tercer lugar al relacionarse sólo con un municipio. En el caso de San Pedro Garza García las actividades de gestión ambiental intermunicipal no están presentes, aunque colaboran con otras instancias gubernamentales de los órdenes federal y estatal como Semarnat, Conafor, Conagua y el PNCM; además del Parque ecológico Chipinque, la iniciativa privada y las universidades. En la figura IV se observan las relaciones intermunicipales vinculadas a la gestión ambiental.

Es relevante mencionar que diversos actores sociales de la región han trabajado en la constitución del Fondo de Agua Metropolitano de Monterrey (FAM), el cual oficialmente se puso en marcha el 19 de septiembre de 2013. Este fondo funciona por medio de un fideicomiso que busca captar recursos financieros para destinarlos a la conservación de los servicios ambientales hidrológicos, fundamentalmente la captación de agua y la retención de sedimentos, a través del mantenimiento y restauración de zonas prioritarias localizadas en el PNCM y otras áreas protegidas por el gobierno del estado de Nuevo León cercanas a la ZMM. 


\section{Figura IV}

\section{Interacción entre municipios}

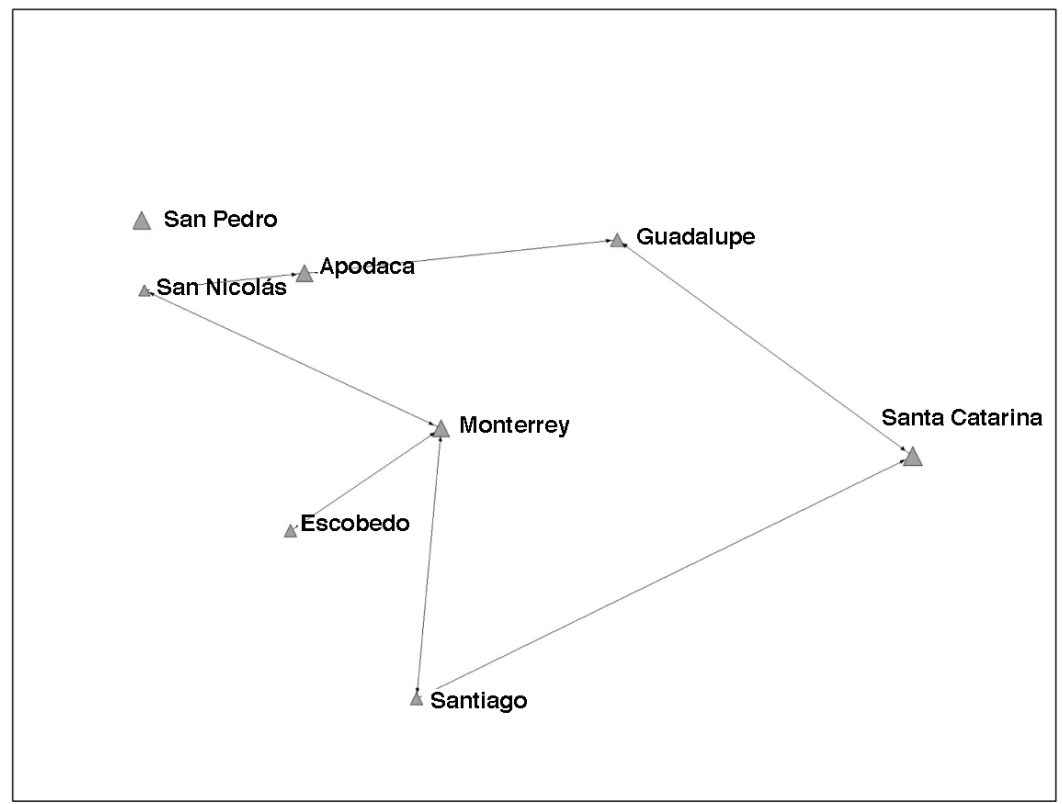

Fuente: elaboración propia.

El fondo empieza a operar con un capital semilla de 300,000 dólares, pero se busca que estos recursos crezcan con las aportaciones y la colaboración de otros actores económicos y sociales locales, a fin de obtener recursos financieros suficientes que contribuyan a la sostenibilidad del fondo en el largo plazo. ${ }^{8}$

El fam es un actor emergente que funciona como puente para el establecimiento de relaciones de colaboración entre diversos actores que anteriormente no estaban interactuando entre sí o que mantenían relaciones de manera bilateral. En la figura $\mathrm{v}$ se observa la estructura de las relaciones generadas a través de este fondo.

El grupo de trabajo del FAM está conformado por actores gubernamentales, no gubernamentales, sector académico e iniciativa privada y ha logrado canalizar esfuerzos a favor de la conservación de las áreas protegidas y los servicios ambientales hidrológicos generando información técnica y científica sobre el funcionamiento y el estado de la cuenca del

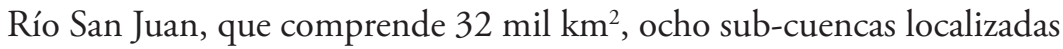
en los estados de Nuevo León (60\%), Coahuila (35\%) y Tamaulipas (5\%), donde la ciudad de Monterrey es el asentamiento de población más im- 


\section{Figura $v$}

\section{Fondo de Agua Metropolitano}

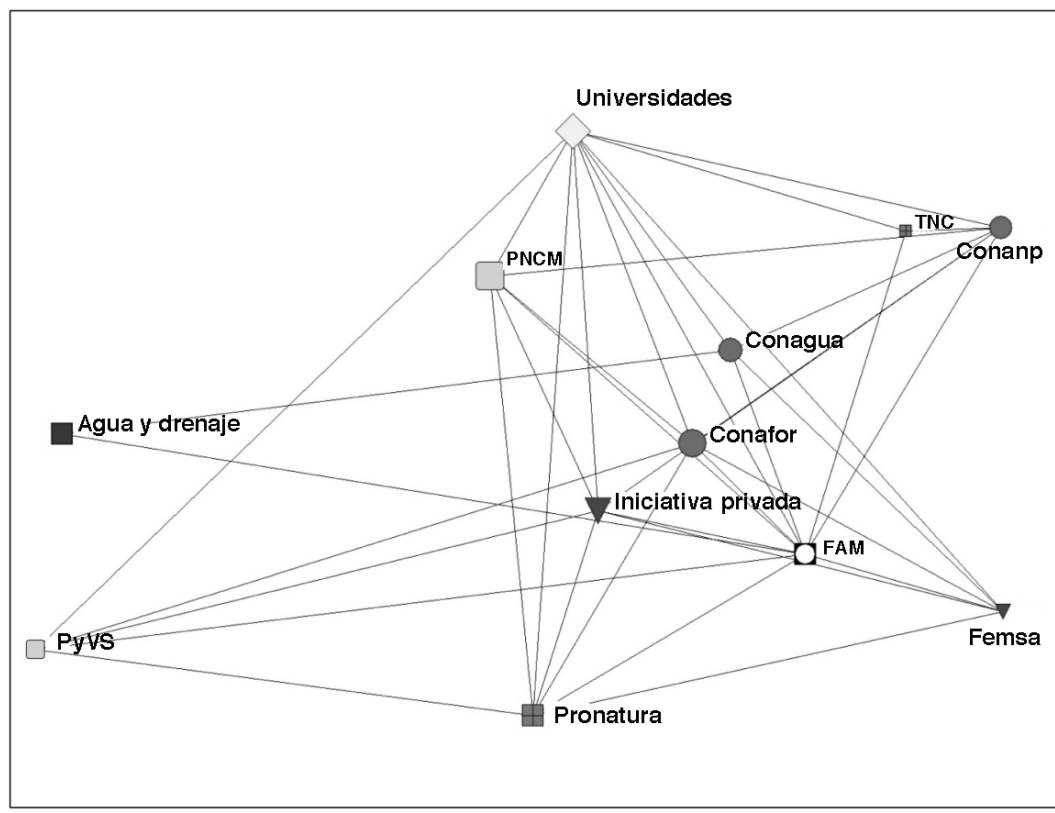

Fuente: elaboración propia.

portante de la región y cuyas acciones de conservación beneficiarán directamente a sus habitantes.

Los estudios realizados han permitido conocer la capacidad de recarga de los acuíferos, los sitios en los que potencialmente se pueden llevar a cabo actividades de reforestación y restauración de ecosistemas. Hasta ahora se han definido algunas áreas prioritarias dentro del PNCM, donde se estima que se capta entre $50 \%$ y $70 \%$ del agua que se utiliza en la ciudad de Monterrey (Saldívar, 2007). Es evidente que la conformación del fam de la ciudad de Monterrey puede contribuir al establecimiento de alianzas estratégicas entre actores sociales y económicos interesados en las acciones de conservación y su operación deberá velar por el interés social que implica la preservación de los recursos naturales y los servicios ambientales que éstos proveen.

Aunque en este análisis no se planteó el objetivo de analizar información sobre la participación y opinión de la sociedad local en los temas de conservación de las ANP y su relevancia para el mantenimiento de los servicios ambientales hidrológicos (principalmente por las restricciones financieras y de recursos humanos disponibles para realizar ese análisis), es relevante destacar las acciones y estudios disponibles realizados por otros actores sociales clave donde se evidencia la importancia relativa que 
tiene para la sociedad local el tema de la conservación de los ecosistemas naturales en la ciudad y sus zonas aledañas.

Por ejemplo, la organización no gubernamental Reforestación Extrema ha jugado un papel relevante en ese sentido, pues a través de su labor busca involucrar a la sociedad civil en la creación, conservación y mantenimiento de áreas verdes dentro de la ciudad. El propósito es reutilizar los espacios públicos con potencial para ser reforestados, para lo cual periódicamente convocan a la sociedad civil a participar voluntariamente en la plantación de árboles. Aunque estas actividades no tienen relación con la gestión o conservación de las áreas protegidas localizadas en la ZMM y su periferia, contribuyen al mantenimiento de servicios ambientales en la ciudad, además de que promueven la participación de la sociedad en la generación y mantenimiento de zonas verdes y espacios públicos, favoreciendo con ello no sólo la construcción de valores ecológicos y el contacto con la naturaleza, sino también el respeto y construcción de diversos valores cívicos: la convivencia, el sentido de pertenencia, la cohesión social y la mejora en la calidad de vida de los habitantes de la ciudad (Falcón, 2007; Borja y Muxí, 2000).

Por otro lado, Saldívar (2007: 8) destaca que en los "resultados de la encuesta realizada a usuarios y operadores del servicio en la zMM durante el mes de octubre de 2007, el noventa y cinco por ciento de la población estaría dispuesta a pagar una cuota mensual por usuario de cinco pesos, lo que corresponde entre diez y cinco por ciento de la tarifa promedio mensual por el servicio de agua potable y alcantarillado". Asimismo, menciona que los usuarios del servicio de agua potable de la ZMM reconocen que los ecosistemas forestales del PNCM contribuyen a la preservación de la provisión de agua (82\%), el aire limpio (82\%), el paisaje y esparcimiento (79\%); sin embargo no reconocen el control de deslaves (26\%) (Saldívar, 2007).

Este último tema atrajo la atención de autoridades municipales y estatales, sobre todo después de lo ocurrido con el paso del huracán Álex, en junio de 2010, que provocó severas inundaciones y pérdidas materiales contabilizadas en 1,885 millones de dólares (Bou-Parés, 2012). ${ }^{9} \mathrm{La}$ posibilidad de que este fenómeno se presente nuevamente como consecuencia del aumento en la frecuencia de eventos meteorológicos extremos se ve agravada por el crecimiento urbano que presiona las áreas de barrancos y cañadas, muchas veces en zonas colindantes a las áreas naturales protegidas localizadas cerca de la ciudad de Monterrey (Saldívar, 2007).

\footnotetext{
${ }^{9}$ En un día la ciudad de Monterrey recibió $446.5 \mathrm{~mm}$ de agua lo que causó el desbordamiento del río Santa Catarina y varios de sus afluentes. Según Conagua el gasto estimado actual de este río en su trayectoria por la zona urbana es de $2,500 \mathrm{~m}^{3} / \mathrm{s}$.
} 
Ante esto, la conservación de las ANP se vuelve una imperiosa necesidad, por un lado para contener el rápido crecimiento de las zonas urbanas, pues se ha demostrado que el cambio de uso de suelo que esto provoca tiene efectos negativos a nivel ecológico en el ambiente (Estoque y Murayama, 2013; Schmidt et al., 2014); y por otro, para que éstas contribuyan a evitar o disminuir los riesgos vinculados a estos eventos, además de proveer múltiples servicios ambientales y convertirse en espacios cada vez más visibles por su importancia ecológica y social tanto para los tomadores de decisiones como para la sociedad en general.

\section{Conclusiones}

A partir de la información empírica reportada es posible observar que las autoridades federales encargadas de gestionar las ANP son las que presentan una mayor integración con distintos actores sociopolíticos regionales. Asimismo, las relaciones formales establecidas entre organismos gubernamentales y no gubernamentales contribuyen a la conservación y gestión de esas áreas, o al menos esa expectativa se genera; por ejemplo con la creación y puesta en marcha del Fondo de Agua Metropolitano de la ciudad de Monterrey.

Estos vínculos son directos y se sustentan en acciones colaborativas. Tanto el PNCM como el MNCS son zonas altamente representativas del paisaje local y nacional, símbolo de la identidad de la ciudad y la región. Asimismo, poseen un gran valor ecológico por los diversos servicios ambientales que aportan, tal es el caso de la conservación del paisaje, la biodiversidad, la captura de carbono y fundamentalmente la provisión de servicios hidrológicos como la captación de agua y la retención de sedimentos.

Las redes de relaciones que han construido los directores de las áreas protegidas federales son más densas y diversificadas que las registradas por las autoridades encargadas de la gestión de las áreas protegidas en Nuevo León, a las que les falta integrar más acciones y procesos con otros actores interesados e involucrados en la conservación de las áreas protegidas. Lo anterior podría generar un flujo de información más eficiente y favorecer la incorporación de aprendizajes de manera más efectiva a nivel colectivo, contribuyendo así al mantenimiento de las áreas protegidas y los servicios ambientales hidrológicos que éstas generan, además de permitir el desarrollo de estrategias conjuntas para lograr la valoración social y prevenir los efectos negativos relacionados con eventos meteorológicos extremos, entre otros.

Las instancias cuyo perfil está claramente definido hacia las actividades de conservación de los recursos naturales (por citar sólo algunos ejemplos 
Conanp, Semarnat, Pronatura, Parque ecológico Chipinque, las direcciones de las ANP, entre otros) llevan a cabo actividades que influyen en la toma de decisiones a favor de la conservación de los ecosistemas y los servicios ambientales hidrológicos, mientras que para las instancias municipales encargadas de los temas ambientales, el tópico de la conservación ocupa un lugar secundario, pues las autoridades centran sus acciones en actividades vinculadas a la educación ambiental, que en la mayoría de los casos es poco visible y prioritaria; las áreas protegidas y en general el asunto de la conservación de los servicios ambientales está ausente en sus agendas de trabajo.

En ocasiones esta falta de atención se debe a que las autoridades se centran en resolver los problemas y abordar temas más apremiantes, además de que carecen de recursos financieros y humanos para atender estos tópicos; lo anterior desincentiva que se centren en la conservación de las ANP, ya que los beneficios que esto puede reportar se evidencian en el mediano y largo plazo.

Fomentar las relaciones intermunicipales, al menos en los casos en los que se comparte la vecindad geográfica con las áreas protegidas, permitiría consolidar un esquema de protección integrado territorialmente, así como sinergias colaborativas en temas de conservación, asimismo, se revertiría la fragmentación en la toma de decisiones entre los gobiernos municipales y otros órdenes de gobierno, además de posibilitar la generación de corredores biológicos y el mantenimiento de las áreas protegidas de manera consistente a lo largo del tiempo.

La operación del faM ha permitido establecer alianzas y vínculos estratégicos entre actores clave gubernamentales y no gubernamentales vinculados e interesados en los temas de conservación y manejo de cuencas. Actualmente, a través de este fondo se busca definir las áreas naturales prioritarias para la conservación y el mantenimiento de los servicios ambientales hidrológicos. Posiblemente, en el futuro, este organismo podrá contribuir a la integración de diversos procesos de gestión de los ecosistemas urbanos y naturales como parte de un paisaje y territorio continuo.

El fondo ha surgido de manera descentralizada respecto a otras iniciativas gubernamentales $\mathrm{y}$, aunque incluye la participación de múltiples actores regionales, persiste el reto de integrar de manera efectiva a la sociedad en general (más allá de la donación de dinero o del pago de una cuota por el servicio ambiental) en el cuidado y conservación de las áreas protegidas para lograr el mantenimiento de diversos servicios ambientales, además de integrar a actores que tradicionalmente no participan en el tema de la conservación como es el caso del sector inmobiliario y de los desarrolladores urbanos. Sin la inclusión de la sociedad en las acciones de 
conservación y en la toma de decisiones no se podrá arribar a una gobernanza ambiental real.

\section{Agradecimientos:}

A Jorge V. Castañeda, por toda su ayuda; a Natalia Zapiain, por su invaluable colaboración en la sistematización de la información; a todas las personas que amablemente me proporcionaron información para realizar este trabajo; a la Universidad Autónoma de Nuevo León y a los revisores anónimos, cuyos comentarios contribuyeron a mejorar este trabajo.

\section{Bibliografía}

Aguilar-Barajas, Ismael (2011), “Urbanización en el área metropolitana de Monterrey: reflexiones sobre sus impactos ambientales. Un análisis hemerográfico sobre el caso del Arco Vial Sureste", en Adrián Guillermo Aguilar e Irma Escamilla (coords.), Periurbanización y sustentabilidad en grandes ciudades, UNAM-IG-ConacytPorrúa, México, pp. 157-189.

Alberti, Marina y John Marzluff (2004), "Ecological resilience in urban ecosystems: linking urban patterns to human and ecological functions", Urban Ecosystems, 7, Kluwer Academic Publishers, The Netherlands, pp. 241-265.

Azuela, Antonio y Paula Mussetta (2009), "Algo más que el ambiente. Conflictos sociales en tres áreas naturales protegidas de México", Revista de Ciencias Sociales, año 1, 16, Universidad Nacional de Quilmes, Buenos Aires, pp. 2-25.

Berkes, Fikret (2002), "Cross-scale institutional linkages: perspectives from the bottom up", en Elinor Ostrom, Thomas Dietz, Nieves Dolsak, Paul C. Stern, Susan Stonich y Elke U. Weber, The drama of the commons, National Academy Press, Washington, pp. 293-321.

Bezaury-Creel J. E., J. Fco. Torres, L. M. Ochoa-Ochoa, Marco CastroCampos, N. Moreno (2009), Catálogo de metadatos geográficos. Comisión Nacional para el Conocimiento y Uso de la Biodiversidad. Base de Datos Geográfica de Áreas Naturales Protegidas Estatales y del Distrito Federal de México, México, 23 de enero de 2015. 
Borja, Jordi y Zaida Muxí (2000), El espacio público, ciudad y ciudadanía, Electa, Barcelona.

Bou-Parés, Elisenda (2012), "Análisis de los huracanes originados entre 1990 y 2011 en el Atlántico Norte y Mar Caribe”, tesis de maestría, Universitat Politécnica de Catalunya, Barcelona, España, <http://upcommons.upc.edu/pfc/handle/2099.1/16290>, 3 de abril 2013.

Cantú, César, Fernando González, José Marmolejo, José Uvalle, David Díaz-Conty, Glafiro Alanís, y David Lazcano (2010), "Consideraciones finales”, en César Cantú, Fernando N. González, José I. Uvalle, José G. Marmolejo, Biodiversidad y conservación del Monumento Natural Cerro de la Silla, UANL-Conabio-Conanp, México, pp. 106-133.

Carruthers, Bruce y Sarah Babb (2000), Economy/society: markets, meanings and social structure, Pine Forge Press, Thousand Oaks.

Cepeda, César (2013), "La guerra por el río", Reporte Índigo. Cinco días, 8 de julio 2013, Capital media, Toluca, <http://www.reporteindigo.com/reporte/monterrey/la-guerra-por-el-rio $>, 8$ de febrero.

Conanp (Comisión Nacional de Áreas Naturales Protegidas) (2014), Catálogo de metadatos geográficos. Comisión Nacional para el Conocimiento y Uso de la Biodiversidad Cobertura representa las Áreas Naturales Protegidas Federales de la República Mexicana, Conabio, México.

Conty-Díaz, David (2010), "Decreto de protección y objetivos de conservación”, en César Cantú A., Fernando N. González, José I. Uvalle, José G. Marmolejo, Biodiversidad y conservación del Monumento Natural Cerro de la Silla, UANL-FCFUANL-MCB-ConabioConanp-Mncs, México, pp. 13-18.

Estoque, Ronald y Yuji Murayama (2013), "Landscape pattern and ecosystem service value changes: implications for environmental sustainability planning for the rapidly urbanizing summer capital of the Philippines", Landscape and Urban Planning, 116, Elsevier, pp. 60-72. 
Falcón, Antoni (2007), Espacios verdes para una ciudad sostenible. Planificación, proyecto, mantenimiento y gestión, Gustavo Gili, Barcelona.

Fang, Liu y Ding Ronggui (2011) "A social network theory of stakeholders in China's Project Governance", iBusiness, 3, Scientific Research Publishing, Wuhan, pp. 114-122.

Fasano, Liliana (2010), Tejiendo redes: el papel de las redes sociales en la salud y el bienestar, Editorial Gran Aldea Editores, Buenos Aires.

Faust, Katherine (2002), "Las redes en las ciencias sociales y del comportamiento", en Jorge Gil Mendieta y Samuel Schmidt, Análisis de redes. Aplicaciones en ciencias sociales, Instituto de Investigaciones en Matemáticas Aplicadas y en Sistemas de la Universidad Nacional Autónoma de México, México, pp. 1-12.

Friedrich, Paul (1991), Los principes de naranja. Un ensayo de método antropohistórico, Grijalbo, México.

Glaeser, Edward (2011), El triunfo de las ciudades, Taurus, México.

Hanneman, Robert y Mark Riddle (2000), Introduction to social network methods, University of California, Riverside, <http://faculty.ucr. edu/ hanneman/Soc157/TEXT/TextIndex.html>, 20 de marzo de 2013.

Harlan, Sharon, Anthony Brazel, Lela Prashad, William Stefanov y Larissa Larsen (2006), "Neighborhood microclimates and vulnerability to heat stress", Social Science \& Medicine, 63 (11), Elsevier, pp. 2847-2863, doi: <http://dx.doi.org/10.1016/j.socscimed.2006.07.030>, 21 de marzo de 2014.

Imperial, Mark (2005), "Using collaboration as a governance strategy. Lessons from six watershed management programs", Administration and Society, 37 (3), Sage, Blacksburg, pp. 281-320.

INEGI (Instituto Nacional de Estadística Geografía e Informática) (2010), Censo General de Población y Vivienda, Inegi, México.

Kazushige, Yamaki (2014), "Network governance of endangered species conservation: a case study of Rebun Lady's-Slipper", Journal for Nature Conservation, Elsevier, Santa Cruz de Tenerife, <http:// 
www.sciencedirect.com/science/article/pii/S161713811400 $1113>, 27$ de febrero de 2015.

Lambin Eric, Patrick Meyfroidt, Ximena Rueda, Allen Blackman, Jan Börner, Paolo Omar Cerutti, Thomas Dietsch, Laura Jungmann, Pénélope Lamarque, Jane Lister, Nathalie Walker y Sven Wunder (2014), "Effectiveness and synergies of policy instruments for land use governance in tropical regions", Global Environmental Change, 28, EfD, Washington, pp. 129-140, doi: <10.1016/j. gloenvcha.2014.06.007>, 28 de febrero de 2015.

Lawrence, Anna, Rik de Vreese, Mark Johntson, Cecil Konijnendijk Van den Bosch y Giovanni Sanesi (2013), "Urban forest governance: towards a framework for comparing approaches", Urban Forestry \& Urban Greening, 12 (4), Elsevier, Alnarp, pp. 464-473.

Melé, Patrice (2003), "Conflits urbains pour la protection de la nature dans une métropole mexicaine”, en Patrice Melé, C. Larrue y Muriel Rosemberg, Conflits et territoires, Presses Universitaires Francois-Rabelais, Tours, pp. 103-117.

Mena Díaz, Néstor (2012), "Redes sociales y gestión de la información: un enfoque desde la teoría de grafos", Ciencias de la Información, 43 (1), Instituto de Información Científica y Tecnológica, Sociedad Cubana de Ciencias de la Información, La Habana, pp. 29-37.

ONU-Habitat (Organización de las Naciones Unidas-Hábitat) (2012), Estado de las ciudades de América Latina y El Caribe 2012. Rumbo a una nueva transición urbana, Programa de las Naciones Unidas para los Asentamientos Humanos, Nairobi.

Ostrom Elinor, Larry Schroeder, Susan Wynne (1993), Institutional incentives and sustainable development. Infrastructure policies in perspective, Westview Press, Colorado.

Saldívar-Valdés, Américo (2007), Estudio de valoración y demanda de servicios ambientales hidrológicos en el área promisoria de Servicios Ambientales, Cumbres de Monterrey y Monterrey, ConaforSemarnat-CNF.

Sedesol-Conapo-INegi (Secretaría de Desarrollo Social-Consejo Nacional de Población-Instituto Nacional de Estadística Geografía e Infor- 
mática) (2012), Delimitación de las zonas metropolitanas de México 2010, Sedesol-Conapo-INEgI, México, <http://www.conapo. gob.mx/en/CONAPO/Zonas_metropolitanas_2010>, 6 de febrero de 2014 .

Schmidt, John Paul, Rebecca Moore y Alber Merryl (2014), "Integrating ecosystem services and local government finances into land use planning: a case study from coastal Georgia", Landscape and Urban Planning, 122, Elsevier, Amsterdam, pp. 56-67, doi: $<10.1016 /$ j.landurloplan.2013.11.008>, 28 de febrero de 2015.

Secretaría de Desarrollo Urbano y Obras Públicas (1999), Áreas naturales de conservación ecológica en el estado de Nuevo León, Subsecretaría de Ecología, Nuevo León.

Stabler, Linda, Chris Martin y Anthony Brazel (2005), "Microclimates in a desert city were related to land use and vegetation index", Urban Forestry \& Urban Greening, 3, Elsevier, Amsterdam, pp. 137-147.

UnEP (United Nations Environment Programme) (2013), UNEP year book 2013: emerging issues in our global environment, UNEP, Nairobi.

Young, Oran R. (2002), "Institutional interplay: the environmental consequences of cross-scale interactions", en Elinor Ostrom, Thomas Diextz, Nieves Dolsak, Paul C. Stern, Susan Stonich y Elke U. Weber, The drama of the commons, National Academy Press, Washington, pp. 263-291.

Zuñiga, Francisco, (2013), "Zapatero a tus zapatos, le dice Margarita a la CNa", Milenio, 19 de julio, Grupo Milenio, México, <http://www. milenio.com/monterrey/Zapatero-zapatos-dice-MargaritaCNA_0_119388093.html>, 4 de febrero de 2014.

\section{Leyes y marcos jurídicos consultados}

LGeEPA (Ley General del Equilibrio Ecológico y Protección al Ambiente) LAENL (Ley Ambiental del Estado de Nuevo León)

LDFSNL (Ley de Desarrollo Forestal Sustentable del Estado de Nuevo León) 
Declaratoria de 23 Áreas Naturales Protegidas con el carácter de zonas sujetas a conservación ecológica del Estado de Nuevo León, 21 de noviembre de 2000 .

Programa de Manejo del Área Natural Protegida en la Categoría de Zona Sujeta a Conservación Ecológica denominada Sierra Corral de los Bandidos, resumen, Periódico Oficial del Estado de Nuevo León, 25 de marzo de 2002.

Programa de Manejo del Área Natural Protegida en la Categoría de Zona Sujeta a Conservación Ecológica denominada Sierra Las Mitras, Resumen, Periódico Oficial del Estado de Nuevo León, 27 de marzo de 2002.

Programa de Manejo del Área Natural Protegida en la Categoría de Zona Sujeta a Conservación Ecológica denominada Cerro La Mota, resumen, Periódico Oficial del Estado de Nuevo León, 27 de marzo de 2002.

Programa de Manejo del Área Natural Protegida en la Categoría de Zona Sujeta a Conservación Ecológica denominada Cerro El Topo, resumen, Periódico Oficial del Estado de Nuevo León, 27 de marzo de 2002.

Programa de Manejo del Área Natural Protegida en la Categoría de Zona Sujeta a Conservación Ecológica denominada Sierra El Fraile y San Miguel, resumen, Periódico Oficial del Estado de Nuevo León, 25 de marzo de 2002.

Programa de Manejo del Área Natural Protegida en la Categoría de Zona Sujeta a Conservación Ecológica denominada Sierra Cerro de La Silla, resumen, Periódico Oficial del Estado de Nuevo León, 27 de marzo de 2002.

Programa de Manejo del Área Natural Protegida en la Categoría de Zona Sujeta a Conservación Ecológica denominada Cerro de Picachos, resumen, Periódico Oficial del Estado de Nuevo León, 27 de marzo de 2002.

Programa de Manejo Programa Estatal de Regeneración, Rehabilitación y Aprovechamiento del Parque Público Cerro del Obispado, resumen, Periódico Oficial del Estado de Nuevo León, 18 de abril de 2008. 
Programa de Manejo del Área Natural Protegida Parque Lineal en Categoría de Parque Urbano, resumen, Periódico Oficial del Estado de Nuevo León, 24 de julio de 2009.

Programa de Manejo del Área Natural Protegida con la Categoría de Monumento Natural El Cerro de la Silla, resumen, Diario Oficial de la Federación, 6 de enero de 2014.

Programa de Conservación y Manejo Parque Nacional Cumbres de Monterrey, borrador, diciembre de 2006.

Recibido: 27 de junio de 2013. Reenviado: 13 de enero de 2014. Aceptado: 28 de agosto de 2014.

Gabriela de la Mora-de la Mora. Mexicana. Es doctora en ciencias políticas y sociales con orientación en sociología por la Universidad Nacional Autónoma de México. Actualmente es investigadora asociada C en el Centro Regional de Investigaciones Multidisciplinarias de la Universidad Nacional Autónoma de México. Es miembro del Sistema Nacional de Investigadores, nivel I. Su línea de investigación actual es Sistemas socio-ecológicos y gobernanza ambiental. Entre sus últimas publicaciones destacan, en coautoría "Legal framework and economic incentives for managing ecosystem services", en Bárbara A. Willaarts, Alberto Garrido y M. Ramón Llamas (coords.), Water for food security and well-being in Latin America and the Caribbean: social and environmental implications for a globalized economy, Routledge, Oxon and New York, pp. 365-384 (2014); Servicios ambientales y propiedad. Análisis sociológico de los procesos de apropiación de la tierra, el agua y el bosque en una comunidad agraria, Plaza y Valdés, México, 189 p. (2013); “¿Lo sólido se desvanece ante el cambio climático? Reflexiones sobre la tragedia del desarrollo y el ambiente", en Jorge E. Brenna Becerril y Francisco Carballo Espejo (coords.), De ruinas y horizontes. La modernidad y sus paradojas, Ítaca-uam unidad Xochimilco, México, pp. 285-304 (2013); "Social property relations and payment for environmental services. A case study in a rural community in Mexico", Culture and Society. Journal of Social Research, 3 (2), Magnus University Press, Kaunas, pp. 11-28 (2012); "Reflexiones sobre los proyectos de compensación por servicios ambientales: una propuesta de análisis", Revista Trayectorias, 32 (13), Universidad Autónoma de Nuevo León, Monterrey, pp. 28-51 (2011). 